\title{
La Asociación Catalana de Salud Laboral (@SCSL) ante el gran reto de la COVID-19
}

\section{The Catalan Society of Occupational Health (@SCSL) facing the big challenge of COVID-19}

\author{
Elisabeth Purtí \\ Joan Inglés ${ }^{1}$ \\ Leyre de la Peña ${ }^{1}$ \\ Maria Cruz Rodríguez ${ }^{1}$ \\ Montserrat Puiggenè ${ }^{1}$ \\ $\mathrm{M}^{\mathrm{a}}$ Carme Bernad ${ }^{1}$ \\ Santiago Calvet ${ }^{1}$ \\ Rosa Maria Orriols ${ }^{1}$ \\ Begoña López ${ }^{1}$ \\ Encarna Martínez ${ }^{1}$ \\ M. Carmen Torres ${ }^{1}$ \\ Sonia Alonso ${ }^{1}$ \\ José $\mathrm{M}^{\mathrm{a}}$ Ramada
}

${ }^{1}$ Associació Catalana de Salut Laboral, Barcelona, España

Fechas · Dates

Recibido: 2020.04 .06

Publicado: 2020.04.15
Correspondencia · Corresponding Author

Associació Catalana de Salut Laboral

Acadèmia de Ciències Mèdiques i de la Salut de Catalunya i de Balears.

Major de Can Caralleu 1-7, 08017 - Barcelona.

scsl@academia.cat 
Con la llegada a España del SARS-CoV-2, el incremento exponencial de enfermos de COVID-19 y sus lamentables consecuencias para un número importante de personas, la @SCSL ha tenido que adaptarse a esta nueva situación. El virus se ha propagado en muchos hogares, en numerosas empresas y en todos los centros sanitarios, sociosanitarios y residenciales del país, llegando incluso a situarnos al borde del colapso asistencial. Esta nueva variable, en forma de riesgo biológico, llegó provocando en la población trabajadora un desequilibrio de la siempre compleja relación bidireccional entre el trabajo y la salud ${ }^{(1)}$. La alta contagiosidad del virus, con una capacidad de propagación muy superior a la que se estimaba inicialmente, ha incrementado el riesgo de enfermar en el trabajo, en paralelo con el propio riesgo ambiental al que todos los ciudadanos están expuestos. No olvidemos que el Centers for Disease Control (CDC) informa de su contagiosidad con un $\mathrm{R} 0=5.7$ frente a una estimación inicial de un $\mathrm{R} 0=2.3-3.3^{(2)}$.

La evolución de la pandemia del SARS-CoV-2, las diversas condiciones de trabajo en los diferentes sectores productivos, los antecedentes de salud de cada trabajador, la carencia de equipos de protección individual (EPIs) y los efectos de los riesgos psicosociales derivados de las largas jornadas de trabajo (en sectores como el sanitario), el posible estado de agotamiento físico, emocional o mental (burnout), los turnos de trabajo, los conflictos de rol y las dificultades en las relaciones interpersonales, han situado a los Servicios de Prevención de nuestro país en la primera línea en la lucha contra esta pandemia.

Ante esta situación, la @SCSL se ha alineado en esta lucha con las autoridades sanitarias y con los profesionales de la salud laboral (técnicos y sanitarios). Se está colaborando con el Departamento de Salud de la Generalitat de Catalunya en diferentes grupos de trabajo y en la elaboración de la "Guia d'actuació i col. laboració dels serveis de prevenció de riscos laborals per fer front a la pandèmia de COVID-19". Se está ofreciendo a diario difusión de las guías, procedimientos y protocolos de actuación de las autoridades sanitarias (Ministerio de Sanidad y Departamentos/Consejerías de Salud de las CCAA) y laborales (Ministerio de Trabajo y Departamentos/Consejerías de Trabajo). Se está difundiendo información contrastada y actualizada al momento, procedente de las principales fuentes de información científica fiable (OMS, CDC, ECDC, NICE, ISC III, EU-OSHA, Epidemix. org, etc.) a través de nuestra web ${ }^{(3)}$ y de la lista de distribución TapiNet.cat ${ }^{(4)}$.

Y recientemente, se ha promovido la creación de dos grupos de trabajo que han elaborado sendos documentos de gran utilidad en la situación actual. El primero lleva por título "Plan de gestión de EPIs en la pandemia COVID-19", dirigido a los profesionales de la salud. Tiene como objetivo dar una respuesta técnica para garantizar la protección de los trabajadores, incluso en aquellos momentos donde puede haber falta de EPIs y poder gestionar esta falta, así como adaptar el uso de mascarillas quirúrgicas y otros EPIs a las necesidades que requiere la pandemia. El segundo lleva por título "Criterios para la gestión de personas especialmente vulnerables y trabajadores/as especialmente sensibles frente al SARS-CoV-2 en las empresas de Cataluña en el contexto de pandemia". Está dirigido a los profesiona- 
les sanitarios de los Servicios de Prevención y tiene como objetivo ofrecer un documento de consenso profesional de la especialidad de medicina del trabajo sobre la identificación y gestión, en un entorno de pandemia, de las personas especialmente vulnerables y trabajadores especialmente sensibles frente a la COVID-19 y al riesgo laboral de exposición al SARS-CoV-2 en las empresas. El documento persigue contribuir a conciliar los derechos a la salud y al trabajo de los trabajadores/as, a cumplir con sus responsabilidades a las empresas y a garantizar los servicios básicos y esenciales a los ciudadanos. Este documento se publica como un Artículo Especial(5) en el presente número de Archivos de Prevención de Riesgos Laborales.

Coincidiendo con la tormenta de la COVID-19, este mes de abril se cumple el primer aniversario de la actual junta de la @SCSL. En efecto, hace un año nos presentamos como un equipo multidisciplinar en el que participamos técnicos/as en prevención de riesgos laborales, enfermeros/as y médicos/as del trabajo con el objetivo común de trabajar por ser el referente para el bienestar laboral de los trabajadores y la consecución de empresas saludables y socialmente responsables. En este viaje de doce meses hemos procurado no perder de vista nuestra misión como sociedad científica, promocionando, desarrollando y divulgando el conocimiento científico, fomentando la calidad en la práctica profesional y promoviendo la incorporación de la cultura preventiva y el valor de la prevención en el conjunto de la sociedad(6).

Siendo fieles a estos principios, la nueva Junta trabajó intensamente en la organización de la XXIX Diada de la @SCSL, celebrada en el área modernista del Hospital de Sant Pau de Barcelona, dando cabida a ponentes de las diferentes especialidades técnicas y sanitarias de la salud laboral( ${ }^{(7)}$. Asimismo, se han organizado sesiones formativas dirigidas a los profesionales de la salud laboral sobre temas de actualidad, impulsando la formación on line en higiene industrial, acreditada por diferentes universidades. Se ha impulsado la actualización de la revista Archivos de Prevención de Riesgos Laborales, renovando la página web, traduciéndola al inglés e integrando la gestión de los manuscritos en el "Open Journal System", lo que facilitará su incorporación futura en las bases de datos de referencias bibliográficas de Scopus ${ }^{(8)}$ y en el Journal Citation Report (Clarivate) ${ }^{(9)}$.

Así pues, las personas de la actual Junta Directiva de la @SCSL están trabajando, y seguirán haciéndolo, para afrontar en cada momento y con rigurosidad los retos que se vayan presentando (como la COVID-19), para lograr la mejora de las condiciones de trabajo y salud de la población trabajadora, al servicio de la comunidad científica y de los profesionales de la salud laboral a los que animamos a aunar esfuerzos a través del asociacionismo, siendo la @SCSL una alternativa con un futuro prometedor que ponemos a vuestra disposición. 


\section{Referencias}

1. Benavides FG, Ruíz-Frutos C, García AM. Trabajo y Salud. En: Ruíz-Frutos C, García AM, Delclos J, Benavides FG. Salud Laboral. Conceptos y técnicas para la prevención de riesgos laborales. $3^{a}$ Edición. Barcelona: Elsevier Masson S.A.; 2007. p. 33-50.

2. Sanche S, Lin YT, Xu C, Romero-Severson E, Hengartner N, Ke R. High contagiousness and rapid spread of severe acute respiratory syndrome coronavirus 2. Emerg Infect Dis. 2020 Jul [date cited]. https://doi.org/10.3201/eid2607.200282

3. Associació Catalana de Salut Laboral [Sitio Web]. COVID-19. Disponible en: http://www.salutlaboral.com/index.php?p=page/html/lasocietat

4. Associació Catalana de Salut Laboral [Sitio Web]. Tapinet. Disponible en: http:// www.salutlaboral.com/?p=page/html/tapinet

5. Associació Catalana de Salut Laboral - Grupo de trabajo para la elaboración de criterios para la gestión de personas especialmente vulnerables y trabajadores/ as especialmente sensibles frente al SARS-CoV-2 en las empresas de Cataluña. (GTPSVTESSARS-CoV-2). Criterios para la gestión de personas especialmente vulnerables y trabajadores/as especialmente sensibles frente al SARS-CoV-2 en las empresas de Cataluña en el contexto de pandemia. Arch Prev Riesgos Labor. 2020;23:234-252.

6. Associació Catalana de Salut Laboral [Sitio Web]. La Sociedad: Visión y Misión. Disponible en: http://www.salutlaboral.com/index.php?p=page/html/lasocietat

7. Associació Catalana de Salut Laboral.XXIX Diada de la @SCSL: Resúmenes de las comunicaciones libres. Arch Prev Riesgos Labor. 2020;23:112-123.

8. Scopus Preview [Sitio Web]. Disponible en: https://www.scopus.com/

9. Journal citation reports - Clarivate [Sitio Web]. Disponible en: http://jcr.clarivate. $\mathrm{com} /$ 